\begin{tabular}{c|c|c}
\hline ISSN 2525-4812 (versão online) & Revista Terceira \\
$\begin{array}{c}\text { ISSN 2238-7641 (versão impressa) } \\
\text { http://www.revistaterceiramargem.com/ } \\
\text { index.php/terceiramargem/index }\end{array}$ & $\begin{array}{c}\text { Recebido em: 19/6/2019 } \\
\text { Aprovado em: } 30 / 2 / 2020\end{array}$ & $\begin{array}{c}\text { Revisaço } \\
\text { Margem Amazônia }\end{array}$ \\
\hline
\end{tabular}

Como citar o artigo:

SANCHES, B. A. S; BILLACRÊS, M. A. R; FERREIRA, B. E. da S. Esboço do uso dos conhecimentos tradicionais e da agrobiodiversidade do Povo Kokama no Alto Solimões. Revista Terceira Margem Amazônia, v. 6, n.15, p. 122-134, 2020. Doi: http://dx.doi.org/10.36882/2525-4812.2020v6i15p122-134.

\title{
ESBOÇO DO USO DOS CONHECIMENTOS TRADICIONAIS E DA AGROBIODIVERSIDADE DO POVO KOKAMA NO ALTO SOLIMÕES
}

\author{
Brian Angelo Sandoval Sanches ${ }^{1}$ \\ Máximo Alfonso Rodrigues Billacrês ${ }^{2}$ \\ Barbara Evelyn da Silva Ferreira ${ }^{3}$
}

\begin{abstract}
Resumo: O povo Kokama do Alto Solimões, mantém o conhecimento tradicional em comunidades indígenas praticando-os na agrobiodiversidade local, tendo a finalidade para uma variedade de formas de usos importantes favorecendo a sua sobrevivência/resistência. A pesquisa teve como objetivo identificar os conhecimentos tradicionais adotados na agrobiodiversidade Kokama no Alto Solimões, buscando mostrar como o conhecimento é praticado e repassado para os mais jovens na agrobiodiversidade local. Para isso, o trabalho teve enfoque na Pesquisa Social (MINAYO, DESLANDES, NETO, GOMES, 2002). O principal resultado é que estes conhecimentos tradicionais são passados de geração em geração principalmente sobre a agricultura, o modo de plantar, épocas corretas, o que mostra a busca pela conservação do modo de vida nas comunidades indígenas analisadas.
\end{abstract}

Palavras-chaves: Conhecimentos tradicionais, agrobiodiversidade, agricultura familiar, indígena kokama.

Abstract: The Kokama people of Alto Solimões, maintain the traditional knowledge in indigenous communities practicing them in local agrobiodiversity, having the purpose for a variety of forms of important uses favoring their survival / resistance. The research aimed to identify the traditional knowledge adopted in the Kokama agrobiodiversity in Alto Solimões, seeking to show how the knowledge is practiced and passed on to the younger ones about local agrobiodiversity. For this, the work focused on Social Research (MINAYO, DESLANDES, NETO, GOMES, 2002). The main result is that this

\footnotetext{
${ }^{1}$ Discente em Geografia, da Universidade do Estado do Amazonas, do Centro de Estudos Superiores de Tabatinga. Estudante do Núcleo de Estudos Socioambientais da Amazônia (NESAM). Bolsista de iniciação científica, pela FAPEAM.

2 Geógrafo, Mestre em Geografia, Doutor em Biotecnologia. Professor da Universidade do Estado do Amazonas, do Centro de Estudos Superiores de Tabatinga. Pesquisador do Núcleo de Estudos Socioambientais da Amazônia (NESAM)

${ }^{3}$ Geógrafa, Mestra em Geografia, Doutoranda em Biotecnologia pena Universidade Federal do Amazonas.
} 
traditional knowledge is passed on from generation to generation mainly on agriculture, the way of planting, correct times, which shows the search for the conservation of the way of life in the analyzed indigenous communities.

Keywords: Traditional knowledge, agrobiodiversity, family farming, kokama indigenous people.

\section{INTRODUÇÃO}

Nos tempos remotos, o povo Kokama não era visto como povo indígena, porque usavam roupas, sabiam ler e escrever e possuíam parentes em outras cidades, como por exemplo, Manaus, definindo-os como ribeirinhos e não indígenas, tendo em sua história um período obscuro e adormecido, razão pela qual nas décadas de 70 e 80 não eram reconhecidos como povo indígena pelos órgãos governamentais, principalmente pela FUNAI (Fundação Nacional do Índio), nesse sentido os seus direitos constitucionais não eram respeitados, assim como suas crenças que as pessoas tinham com os seus mestres ancestrais. (OGCCIPK, 2010).

Por outro lado, também eram bem pouco assistidos pelas organizações do Governo Federal, Estadual e Municipal. O povo Kokama no Alto Solimões lutava e só queria ter o seu reconhecimento, considerados por muitos como ribeirinhos, os Kokamas só queriam ser o que verdadeiramente são, isto é, indígenas (OGCCIPK, 2010).

Na década de 90, os Kokamas criaram uma organização chamada Coordenação de Apoio aos Índios Kokamas no Amazonas (COIAMA), com a sede principal em Manaus, fundada por lideranças Kokama, após 4 anos de sua criação começou a surgir divergências entre políticos e indígenas, e assim as lideranças que criaram a COIAMA se afastaram e não interferiram na organização (OGCCIPK, 2010).

Buscando reforçar a luta pelos seus direitos, as lideranças Kokama se organizaram novamente e criaram a Organização Geral dos Caciques das Comunidades Indígenas do Povo Kokama (OGCCIPK), criada com o objetivo principal de resgatar a cultura e a demarcação de suas terras, assim como o direito ao acesso a programas diferenciados de educação e saúde. E todo esse processo de movimento indígena Kokama começou na Comunidade Indígena Kokama de Sapotal (Tabatinga, Amazonas), por isso que dentre alguns professores e moradores a consideram como "A Raiz do Povo Kokama" ou "O Berço do Povo Kokama” (OGCCIPK, 2010). 
Sendo assim, todo esse processo serviu para que o povo Kokama fosse reconhecido como povo indígena, da etnia Kokama, buscando ter a sua terra demarcada, ser atendido na educação e saúde, desde que não se perca a cultura. Hoje em dia, o povo Kokama é atendido tanto na educação quanto na saúde, porém, ainda necessita de melhorias para que não se perca a sua língua materna e subsequente a etnia, que é carregada de práticas culturais peculiares de cada grupo indígena, no qual se produzem e reproduzem, conforme o modo como são repassados os conhecimentos tradicionais.

Um dos modos de se identificar isto ocorre pelas práticas agrícolas, onde o povo indígena Kokama, desenvolve por meio de seus conhecimentos tradicionais a produção e reprodução do espaço em que vivem, o seu modo de viver e resistir, ou seja, o seu modo de vida, que é o "modo como produzem e o que produzem", assim, o "que eles são coincide, portanto, com sua produção, tanto com o que produzem como o modo como produzem, o que os indivíduos são, por conseguinte, depende das condições materiais de sua produção" (MARX, 1932, p. 44).

Diante do exposto, como ocorre a produção do espaço do povo Kokama no Alto Solimões, no município de Tabatinga/AM, mediante os conhecimentos tradicionais relacionados com a agrobiodiversidade?

Desta forma, o objetivo deste trabalho é identificar os conhecimentos tradicionais adotados na utilização agrobiodiversidade Kokama no Alto Solimões, em Tabatinga. Os conhecimentos tradicionais se apresentam como condições geográficas, sociais, ecológicas, políticas e econômicas, que envolvem a caracterização de cada região. De forma que estas práticas espaciais manifestam as necessidades de cada formação sócioespacial, que foram ou são satisfeitas, conforme, os recursos (naturais, tecnológicos, financeiros e outros) predispostos.

\section{METODOLOGIA}

Em busca de identificar os conhecimentos tradicionais propagados no uso da agrobiodiversidade Kokama, no alto Solimões, foram adotadas técnicas de pesquisa social (MINAYO, DESLANDES, NETO, GOMES, 2002), desta forma os elementos metodológicos utilizados foram:

- Levantamento bibliográfico: a finalidade foi complementar a fundamentação teórica do projeto, enfatizando que o levantamento bibliográfico tende a aprimorar e melhorar ainda mais o desenvolvimento do trabalho. 
- Definição da amostragem: foram realizadas 31 entrevistas no total. Sendo realizadas da seguinte forma: 15 na comunidade de Sapotal, 6 na Comunidade Luiz Ferreira, ambas em Tabatinga e 10 na Comunidade Bom Jardim II, em Benjamin Constant (Figura 1). Mas a pesquisa não se baseou em aspecto numéricos e sim nos sujeitos sociais que utilizam a agrobiodiversidade.

- Pesquisa de campo: foram feitos registros fotográficos e aplicação de entrevistas informais.

- Organização e análise dos dados: analisou-se e interpretou-se os dados, correlacionando com as pesquisas bibliográficas, com enfoque geográfico, econômico e social.

Figura 1: Mapa de localização das Comunidades de Bom Jardim, Sapotal e Luis Ferreira

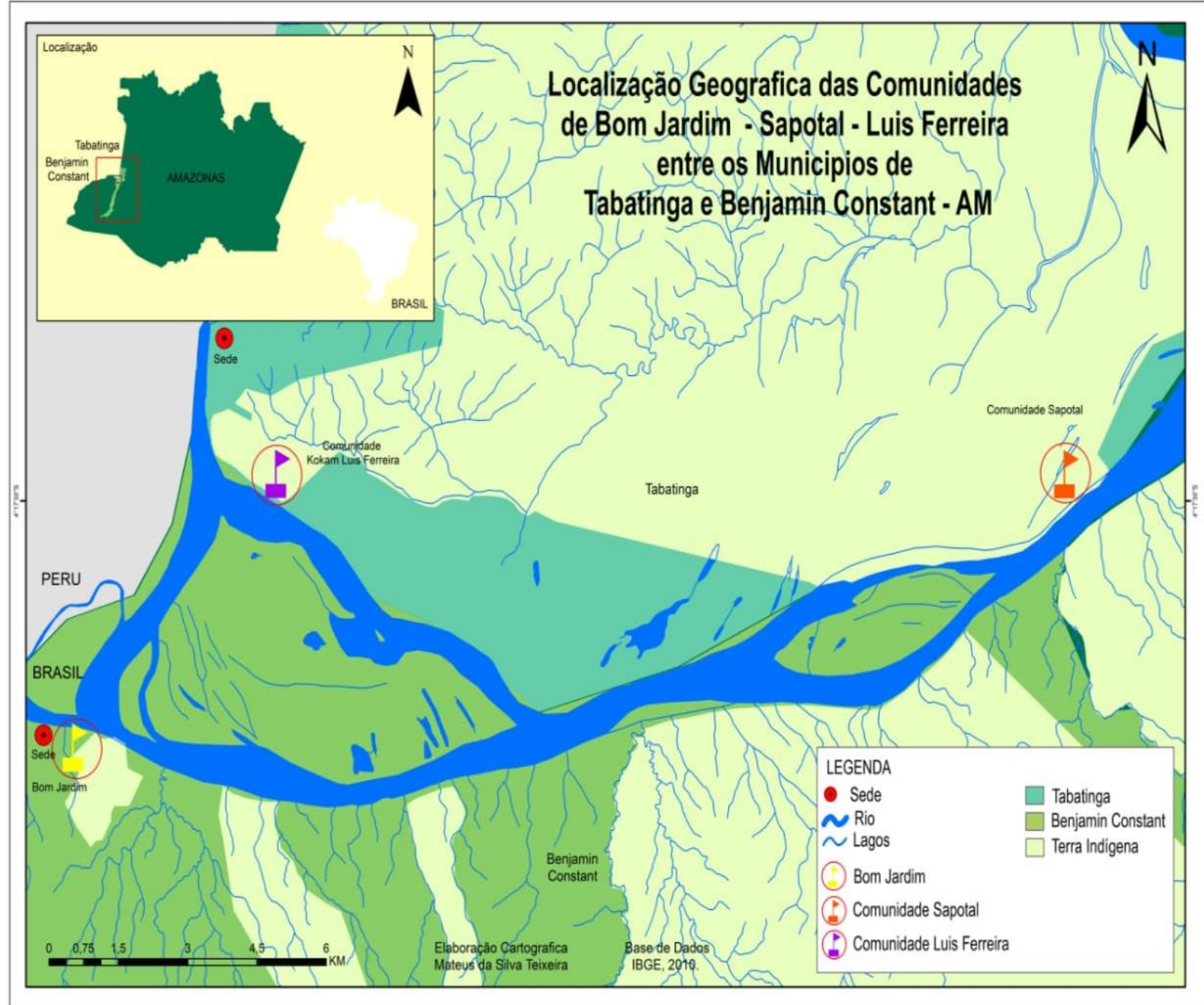

Fonte: SANCHES, 2020 


\section{FUNDAMENTAÇÃO TEÓRICA}

\section{Generalidades dos conhecimentos tradicionais Kokama}

Os indígenas Kokama são conhecidos como andarilhos, pois se deslocavam de um lugar para outro frequentemente, em busca de um ambiente e local agradável para a produção e reprodução do seu modo de vida (ALMEIDA E RUBIM 2012 apud RUBIM, 2016, p. 29).

Ao passo, que foram registrados por viajantes e cronistas desde o século XVI, que conforme, Rubim (2016) esses registros interessaram pesquisadores brasileiros, colombianos e peruanos. Apresentaram em seus estudos e há relatos ainda hoje (no Brasil, Colômbia e Peru), que os Kokama constituíam um povo que vivia em constante movimento, sendo assim, considerados nômades. Este processo de deslocamento do povo Kokama tem sido sempre comentado, como atrelado a conflitos na busca de terras, para plantio e de águas para o exercício da pesca (RUBIM, 2016, p. 29).

Segundo Freitas (2002 apud RUBIM, 2016, p. 29), “os Kokama residiam às margens dos rios, conforme foi registrado pelos viajantes e cronistas, 'como um povo que sempre buscou residir em áreas próximas aos rios"'. Dessa maneira, são encontrados nas margens do rio Solimões, localidades (comunidades - termo utilizado regionalmente) de povos indígenas Kokama, que se instalam nestas localidades por terem a disposição terras (para a agricultura) e água (para a pesca).

Neste sentido, de modo direto ou indireto, os conhecimentos tradicionais se apresentam por meio de práticas do dia-a-dia, experimentações e inovações que estão em dinâmica aparição para a produção de um fim, transitadas e transmitidas de geração em geração, procurando fortalecer o conhecimento para que não se perca futuramente, sabendo-se que é um dom de representatividade das comunidades indígenas, mantendo e constituindo a memória e a história viva do povo (BERTOLDI e SPOSATO, 2012, p. 79).

Os conhecimentos tradicionais sobre a biodiversidade contêm uma variedade de finalidades importantes para as comunidades indígenas, a biodiversidade local tem funções múltiplas que vão desde o uso como alimentos e medicamentos, até o desenvolvimento de conhecimentos e práticas para a agricultura, a pesca e a criação de animais, o que é presenciado frequentemente nas comunidades indígenas dentre os agricultores e pescadores indígenas. 
Agricultura sem biodiversidade é muito difícil, são quase que inseparáveis devido ao conjunto de práticas que envolvem a espacialização da agricultura, além de sua importância no processo de formação territorial e social da sociedade brasileira e amazonense, a atividade agrícola faz parte da estrutura (social, econômica e política) dos grupos e comunidade com as mais diversas paisagens, como por exemplo, proteção e criação de espaços e biodiversos. (COSTA e NUNEZ, 2017, p. 10).

Desse modo, os conhecimentos tradicionais se apresentam como condições geográficas, sociais, ecológicas, políticas e econômicas, que envolvem a caracterização de cada região. De forma que estas práticas espaciais manifestam as necessidades de cada sociedade, que foram ou são satisfeitas conforme os recursos (naturais, tecnológicos, financeiros e outros) predispostos.

Desta maneira, a agrobiodiversidade é o processo no qual o homem caça e coleta alimentos na natureza para cultivar a terra e criar animais, fomentando uma produção para consumo próprio, em que o mesmo conserva o ambiente (SANTILLI, 2009).

Para esclarecimentos, o conceito de agrobiodiversidade se apresenta como distinto de biodiversidade, mas se enquadra como uma derivação de mesmo, visto que o entendimento de biodiversidade é constituída pelo conjunto dos seres vivos, pelo seu material genético e pelos complexos ecológicos dos quais eles fazem parte" (LEVEQUE, 1999).

Desta forma, nas comunidades indígenas a agricultura familiar é a que predomina como forma de relação com a agrobiodiversidade, visando que a mesma contribui tradicionalmente com a cultura da comunidade. Noda e Noda (2003, p. 55) sustentam que “as formas de produção da agricultura familiar têm em suas raízes a contribuição cultural das populações tradicionais. As populações indígenas desenvolveram sistemas de manejo que integram a agricultura a diversos ambientes e recursos da região amazônica".

Assim sendo, Costa e Nunez (2017, p, 8) argumentam que, "a agricultura familiar camponesa trabalha muito com as funções ecológicas naturais, que torna desnecessário o uso de muitos dos insumos químicos (pesticidas, fertilizantes, entre outros)".

Guanziroli (2009, p. 16-17), “os agricultores familiares são sensíveis aos estímulos de mercado, absorvem tecnologia moderna e produzem eficientemente podendo, portanto, produzir alimentos e matérias-primas em quantidade e qualidade requeridas pela expansão do setor urbano industrial".

Neste contexto, os agricultores familiares com o uso de tecnologia, tem a finalidade de usar para ponderar eficientemente o seu trabalho e ter uma produção em 
grande quantidade, visto que as comunidades indígenas tradicionais usam diretamente a mão-de-obra.

\section{RESULTADOS E DISCUSSÃO}

A pesquisa de campo foi desenvolvida em três comunidades kokama, que são as comunidade de Sapotal e Luís Ferreira em Tabatinga (AM), e sendo feita uma pesquisa no município de Benjamim Constant-AM, na comunidade de Bom Jardim II, cuja pesquisa foi realizada com o objetivo de aprofundar e identificar ainda mais os conhecimentos tradicionais e agrobiodiversidade entre os dois municípios.

\section{Comunidade de Sapotal}

A Comunidade Indígena Kokama de Sapotal, localizado na região Norte do Brasil, pertence ao município de Tabatinga-AM, se encontra a margem esquerda do rio Solimões. A pesquisa foi desenvolvida buscando colher dados acerca dos conhecimentos tradicionais e agrobiodiversidade da comunidade, sabendo que as pessoas da mesma possuem.

Em Sapotal os indígenas vivem da agricultura familiar e da pesca, e se enquadram no conceito de camponês, sabendo que na agricultura eles plantam e colhem o produto, muitas das vezes para consumo da família e as vezes para venda, e quando ocorre a venda é para comprar um produto que ele não produz e que não tem na comunidade, visto que uma das características do modo de vida camponês é da "transferência de uma parte da produção camponesa para a feira da cidade próxima” (MOURA, 1986, p. 57). Outras características são o trabalho familiar, a ajuda mútua, entre outras.

Segundo os moradores desta comunidade, a agricultura possui uma diversidade biológica de plantas que eles cultivam como a: Mandioca, Macaxeira, Banana, Milho, Pimentão e Pimenta cheirosa (Figura 2) entre outros, prevalecendo a plantação de Mandioca, Macaxeira e Banana (Figura 3). 
SANCHES, B. A. S; BILLACRÊS, M. A. R; FERREIRA, B. E. da S

Figura 2: Pimentão e Pimenta cheirosa

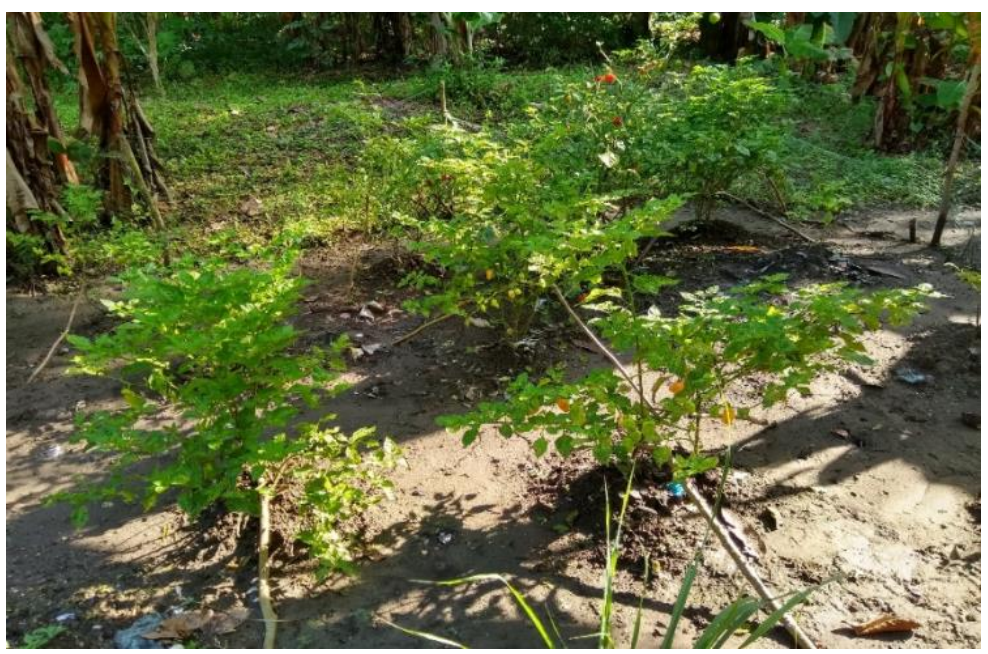

Fonte: autores, 2020

Figura 3: Banana (Língua Kokama = Panara)

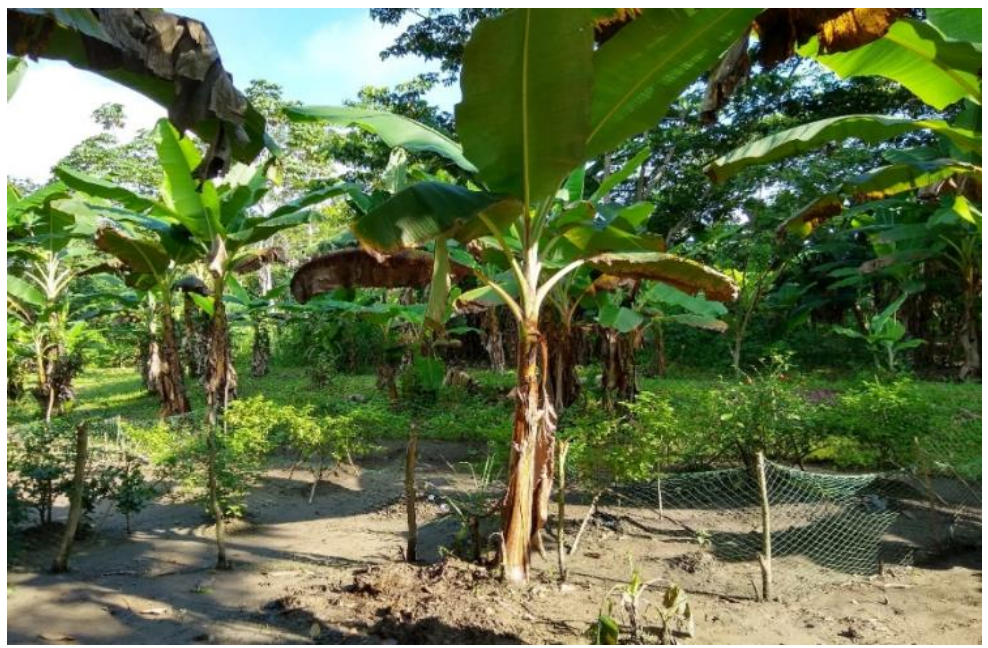

Fonte: autores, 2020.

Os moradores enfatizaram que os conhecimentos tradicionais são repassados no dia-a-dia, seja ela na roça ou em casa, e o modo de transmitir ocorre por meio da fala, da imitação e da praticidade, procurando resguardar o conhecimento para que não se perca, por ser muito importante na agricultura e para a cultura de um modo geral da comunidade.

\section{Comunidade de Bom Jardim II}

A Comunidade Kokama de Bom Jardim é localizada no município de Benjamin Constant/AM, se encontra a margem direita do rio Solimões. A pesquisa foi desenvolvida buscando por meio dos dados identificar os conhecimentos tradicionais $\mathrm{e}$ agrobiodiversidade. 
Na comunidade Bom Jardim II, os indígenas desenvolvem a criação de animais, no quintal (Figura 4), a agricultura e a pesca, em que na agricultura familiar cultivam várias plantas segundo informações dos mesmos, como a: Mandioca, Macaxeira, Banana, entre outros, com isso cultivam a maioria para consumo (Figura 5) e pouco para venda.

Figura 4: Quintal dos moradores para a criação de animais

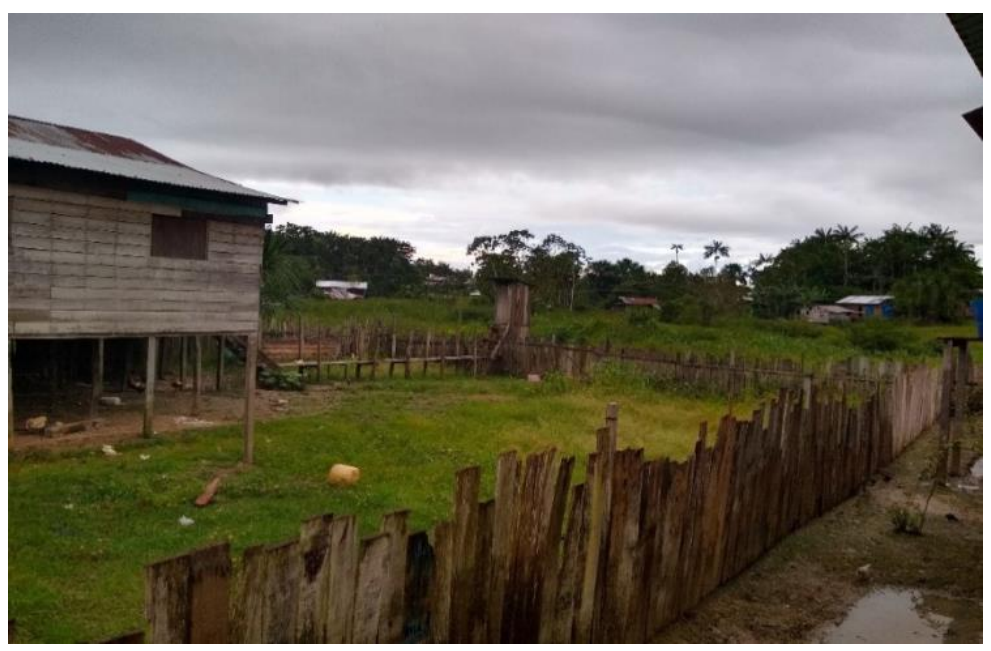

Fonte: autores, 2020.

Figura 5: Mulher Indígena Kokama mexendo a massa de Mandioca

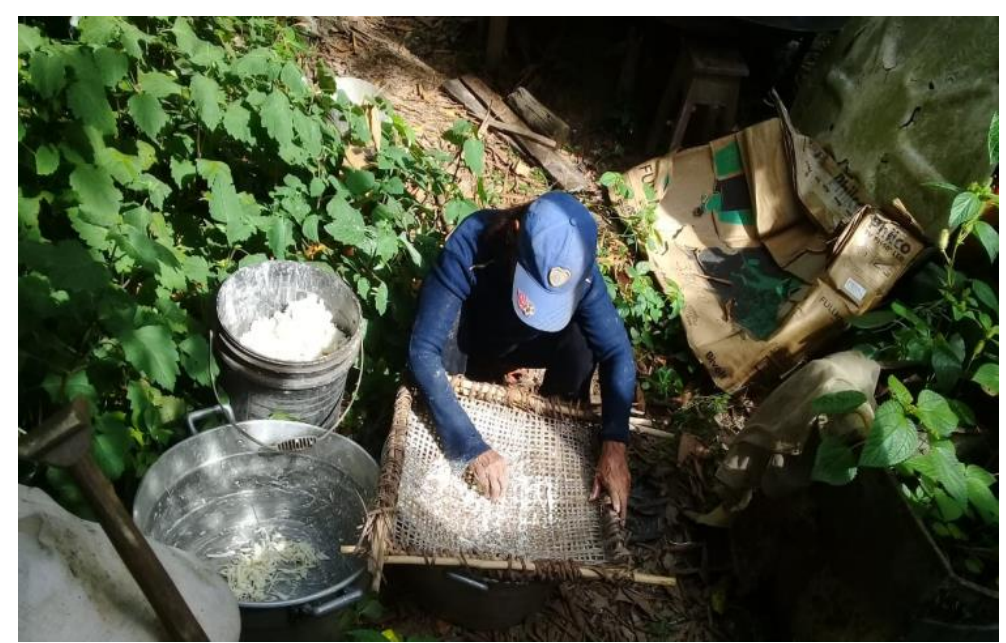

Fonte: autores, 2020.

Os conhecimentos tradicionais são transmitidos por meio oral, por imitação e prática, em que os indígenas mais jovens estão adquirindo das pessoas mais idosas, ao que tudo indica que o conhecimento tradicional se repassa de geração em geração, observou-se na comunidade que as pessoas procuram não perder os conhecimentos, mas que alguns jovens não dão valor a cultura local e alguns costumes acabam sendo perdidos. 


\section{Comunidade de Luís Ferreira}

A Comunidade Indígena Kokama de Luís Ferreira, pertence ao município de Tabatinga-AM e se encontra a Sudeste terminando o perímetro urbano da cidade de Tabatinga. Esta localidade ainda está em processo de organização, da mesma, como comunidade.

Visto que são caracterizados por arranjos produtivos, e formas de gestão de recursos naturais, onde a organização social e econômica é fundada no parentesco e na apropriação comunal dos recursos naturais existentes (NODA et all, 2012)

Nas comunidades indígenas sempre é encontrada uma casa de encontro, que segundo os moradores desta comunidade é muito importante (Figura 6), pois, é aí em que eles se encontram para discutir situações relevantes que envolvem a comunidade, como a questão da agricultura que é um aspecto importante para a mesma, por ser da agricultura que os moradores usufruem algo para consumir e viver do seu modo.

Figura 6: Casa de encontro para reuniões dos moradores

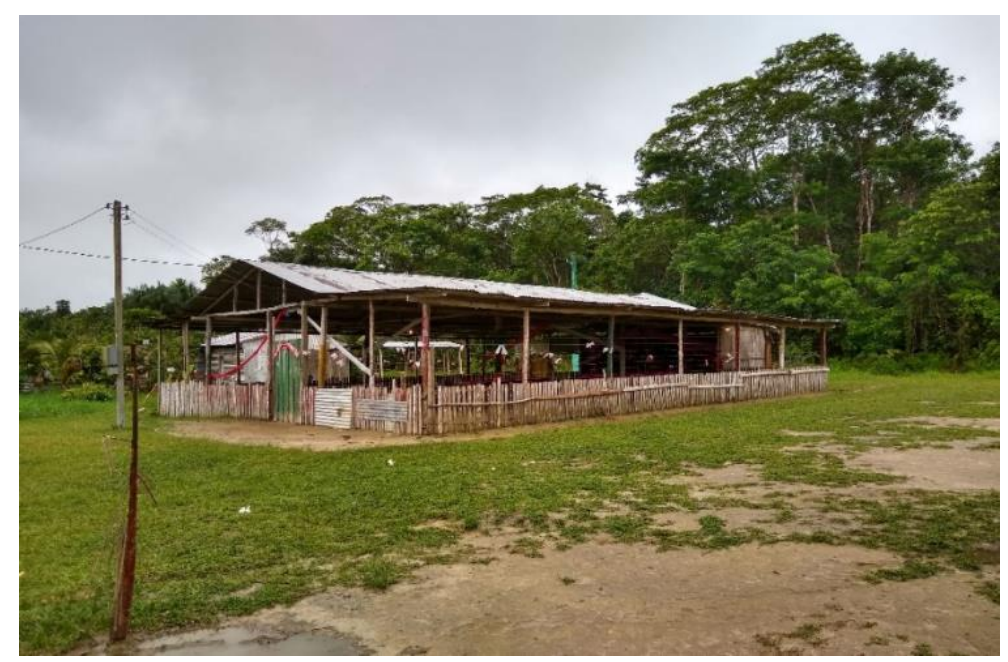

Fonte: autores, 2020.

Sendo cultivada na agricultura a Mandioca, Macaxeira, Banana, Mapati, Abacaxi, entre outros, estes cultivos são produzidos pelos moradores, que se servem com predominância e frequência.

Esse conhecimento tradicional que as pessoas têm sobre quando plantar e quando colher está sendo repassado para as pessoas mais jovens, no qual a transmissão acontece por meio da oralidade, imitação e prática, onde os jovens adquirem para conservar, cuidar e levar em frente o conhecimento que é um patrimônio cultural do povo Kokama. 
Em suma, para que as comunidades indígenas tenham um valor e relevância em meio a sociedade, acerca de seus conhecimentos tradicionais sobre a agrobiodiversidade, e para que tenham sempre em processo a reprodução do seu modo de vida, segundo Costa e Nunez (2017, p. 23), “tem que se ter a conquista do apoio de instituições públicas e políticas públicas como espaços de defesa de sua realidade social, econômica e política".

Pois, na realidade não existe um claro desenvolvimento de políticas públicas nas comunidades kokama do Alto Rio Solimões, não tem órgãos de Governo que incentivem, por exemplo, na parte do comércio, para poder assim comercializar os produtos dos agricultores Kokamas das comunidades, como a mandioca, a banana, a macaxeira, o feijão, o milho e outros produtos agrícolas, tendo em vista a importância e o valor que poderia dar a produção agrícola dos indígenas.

Da mesma forma, no social também não existe políticas públicas especificas para os povos indígenas, ao não ser o geral que são a bolsa família, que os pais de família recebem para a subvenção de material escolar dos filhos, que é bom do órgão federal que chega através dos municípios, e da mesma forma no ambiental não existe políticas públicas voltado para ajudar os indígenas a preservar e cuidar dos recursos hidrobiológicos, flora e fauna.

\section{CONSIDERAÇÕES FINAIS}

A forma como é utilizada os conhecimentos tradicionais é relevante, pois, é interessante pesquisar acerca como esse conhecimento é usado pelas pessoas que as obtém, quando e em que momento as utilizam, frisando que qualquer conhecimento, que seja, tem um poder enorme, isto é de mover ou de transformar um determinado objeto ou matéria-prima em recursos que venham a ser consumidos pelo homem.

Nesse sentido, a pesquisa nos incorporou a problemática de colher informações nas três comunidades supracitadas, para conhecer e identificar os conhecimentos tradicionais adotadas pelas pessoas indígenas sobre a agrobiodiversidade que as mesmas cultivam.

No entanto, os órgãos de governo federal são os mais responsáveis por desenvolver políticas públicas para ajudar os povos indígenas do Brasil, para assim eles puderem ter outra visão de mundo e assim adquirir os conhecimentos necessários e assim ter mais recursos para poder cuidar e preservar os recursos naturais de forma sustentável. 


\section{AGRADECIMENTOS}

A Fundação de Amparo à Pesquisa do Estado do Amazonas-FAPEAM, pelo financiamento, do tipo bolsa de iniciação científica.

\section{REFERÊNCIAS}

BERTOLDI, M. R.; SPOSATO, K. B. Instrumentos de Proteção dos Conhecimentos Tradicionais associados à Biodiversidade. Revista de Direitos Fundamentais e Democracia, Curitiba, v. 12, n. 12, p. 75-93, julho/dezembro de 2012. ISSN 1982-0496.

COSTA, R. C.; NUNEZ, C. V. Biodiversidade e Cadeia Produtivas: Potencialidades sinérgicas. In: COSTA, Reinaldo Corrêa; NUNEZ, Cecília Verônica. Cadeias Produtivas \& seus ambientes. (Organizadores). -- Manaus: Editora INPA, 2017.

GUANZIROLI, C. E. Agricultura familiar e reforma agrária no século XXI / Carlos E. Guanziroli [ap. al.]. / Rio de Janeiro: Garamond, 2009. 16x23 em; 288 p.

LÉVÊQUE, C. A Biodiversidade / Christian Lévêque; tradução: Waldo Mermelstein Bauru, SP: EDUSC, 1999. 246p.; 18cm. - Humus.

MARX, K.; ENGELS, F. A ideologia alemã: Feuerbach - A contraposição entre as cosmovisões materialista e idealista. Coleção: A obra prima de cada autor, versão original 1932. Ed: Martin Claret, 2006;

MINAYO, M. C. S.; DELANDES, S. F.; GOMES, R. Pesquisa social: teoria, método e criatividade. 21. ed. Petrópolis: Editora Vozes, 2002

MOURA, M. M. Camponeses. São Paulo: Editora Ática S. A., 1986;

NODA, Sandra do Nascimento; MARTINS, Ayrton Luiz Urizzi; NODA, Hiroshi; SILVA, Antonia Ivanilce Castro da; BRAGA, Maria Dolores Souza. Paisagens e etnoconhecimentos na agricultura Ticuna e Cocama no alto rio Solimões, Amazonas. Boletim do Museu Paraense Emílio Goeldi. Ciências Humanas, v. 7, n. 2, p. 397-416, maio-ago. 2012.

NODA, H.; NODA, S. do N. Agricultura familiar tradicional e conservação da sóciobiodiversidade amazônica. Hiroshi Noda e Sandra do Nascimento Noda. Instituto Nacional de Pesquisas da Amazônia - INPA. Revista Internacional de Desenvolvimento Local. Vol. 4, N. 6, p. 55-66, Marr. 2003.

Organização Geral dos Caciques das Comunidades Indígenas do Povo Kokama OGCCIPK, 2010.

RUBIM, A. C. O reordenamento político e cultural do povo Kokama: a reconquista da língua e do território além das fronteiras entre o Brasil e o Peru / Altaci Corrêa Rubim; orientador Enilde Leite de Jesus Fausltich. - Brasília, 2016. 324 p.

SANTILLI, J. Agrobiodiversidade e direitos dos agricultores/Juliana Santilli. - São Paulo: Peirópolis, 2009. 